\title{
Palabras de final de gestión
}

\author{
Words at the end gestion
}

REVISTA ARGENTINA DE CIRUGÍA PLÁSTICA 2019;25(1):37. DOI/10.32825/RACP/201901/0037-0037

Culmina un año al frente de SACPER, con la satisfacción de haber trabajado con libertad y cumpliendo con la mayoría de los objetivos planteados.

La gestión tuvo un elemento fundamental, que fue la conectividad, gran aliado que permitió una comunicación directa y con un mínimo costo entre los asociados. Tal el caso de las reuniones de Comisión Directiva por videoconferencia, el Curso Anual de Actualización online con récord de inscriptos, las reuniones conjuntas y simultáneas con los presidentes de las nueve regionales, las encuestas entre los asociados y una webinar para dar a conocer el proyecto de modificación del estatuto.

Dicho proyecto, consensuado entre los referentes de cada regional y aprobado en Asamblea, tuvo como principal objetivo hacer crecer a SACPER y adaptarla a los tiempos actuales.

Queda mucho por hacer y estamos convencidos de que la continuidad de las políticas implementadas permitirá seguir avanzando para que SACPER sea una sociedad con mayor representatividad y fortaleza, cualidades necesarias para ser influyente en esta etapa donde nuestra especialidad se encuentra amenazada.

Felicito al Dr. Gustavo Grgicevic por su labor como editor de la Revista Argentina de Cirugía Plástica y estimulo a todos aquellos colegas a que envíen sus trabajos para nutrirla de conocimiento. Asimismo, agradezco de todo corazón a todos aquellos que entendieron que el trabajo grupal es la única manera de salir adelante y progresar como sociedad. 